\title{
Electronic and Spectroscopic Study of the GaAs nitridation - Electronic Characterization Associated
}

\author{
Nacera Bachir Bouiadjra \\ AMEL, Djillali Liabès \\ university
}

Sidi Bel Abbès, Algeria

\author{
Zineb Benamara \\ AMEL, Djillali Liabès \\ university \\ Sidi Bel Abbès, Algeria
}

\author{
Christine Robert \\ LASMEA, UMR 6602 \\ Avenue des Landais, 63177, \\ Aubière CEDEX, France
}

\author{
Abdelkrim Sellam \\ IRECOM Laboratory, Djillali \\ Liabès university \\ Sidi Bel Abbès, Algeria
}

\author{
Bernard Gruzza \\ LASMEA, UMR 6602 \\ Avenue des Landais, 63177, \\ Aubière CEDEX, France
}

\begin{abstract}
Gallium nitride is one of the III-V semiconductors the most promising in many application areas. Indeed, because of its large direct bandgap $(3,4 \mathrm{eV})$, it can be dedicated to both optoelectronic applications as transistors achieve hyper frequency. It allows the manufacture of components stable at high temperatures and high frequencies. In this work we are interested in the nitriding of gallium arsenide substrates of n-type in order to obtain a thin layer of GaN. The samples were chemically cleaned immediately introduced into the chamber ultra-high vacuum. They then undergo ionic cleaning in situ by argon ions. Spectrometric analyzes do show the absence of any impurities from the surface, in fact, it only detects the presence of gallium and arsenic. Before proceeding to the nitriding of our structures, deposition of gallium is conducted for 20 minutes to send then simultaneously nitrogen and gallium. Analyzes were performed elaborate structures using X-ray photoelectron spectroscopy (XPS). Deposition of mercury (Hg) has been developed on the structures, we have then made an electrical characterization I-V to see the effect of nitriding on the resulting structure.
\end{abstract}

Key words: GaAs, GaN, XPS, I-V characterization, Schottky diode.

\section{Introduction}

A nitridation of GaAs is intensively studied in the last years as the first step of GaN layer deposition or a method for stabilization and passivation of a GaAs surface. Chemical and structural studies on a GaAs surface during and after nitridation

In this paper, we are interested in the nitridation of GaAs to obtain a Schottky diode rectifier perfectly.

The I-V characteristic shows that our structure are Schottky diode rectifier whose electrical parameters are determined by a fitage of different regions of the characteristic; for our structure, we have determined the values of the series resistance, parallel resistance and the saturation current which are respectively $13 \Omega, 500 \Omega$ et $2,5 \cdot 10^{-6} \mathrm{~A}$.

\section{Sample Preparation}

\subsection{Cleaning samples :}

The gallium arsenide substrates used were commercial substrates which are in the form of circular plates of thickness of $400 \mu \mathrm{m}$ and a diameter of about $50 \mathrm{~mm}$. These substrates were made by Czochralski pulling and then cut along the (100) orientation. These samples are doped n-type carrier concentration is $\mathrm{N}_{\mathrm{d}}=1,4 \times 10^{18}$ atomes $/ \mathrm{cm}^{3}$. It is necessary to chemically clean the substrates as they contain various impurities such as oxides and fats.

The samples chemically cleaned were immediately introduced into the chamber ultra-high vacuum. They then undergo ionic cleaning in situ and characterized by photoelectron spectroscopy (XPS). All spectra were performed under excitation with X skate MgK $\alpha$ with energy hv $=1253,6 \mathrm{eV}$.
To our experience, the ion cleaning with $\mathrm{Ar}+$ ions, is carried out with an argon ion kinetic energy of $1 \mathrm{keV}$, a current density of $3.8 \mu \mathrm{A} / \mathrm{cm}^{2}$ beam, argon pressure in the chamber of $4.10^{-5}$ Torr with a cleaning time of $60 \mathrm{~min}$.

\subsection{Study of the evolution of the Ga3d transition}

Figures 1 and 2 show respectively the $\mathrm{Ga}_{3 \mathrm{~d}}$ transition after chemical cleaning and after cleaning ion respectively. We have broken this transition in a single peak as the difference in energy doublet $\mathrm{Ga}_{3 \mathrm{~d} 5 / 2} \mathrm{Ga}_{3 \mathrm{~d} 3 / 2}$ related to the spin-orbit coupling is small $(0.44 \mathrm{eV}){ }^{[1,2,3]}$. The peak position associated with the GaAs link is located at 19,2 $\pm 0,2 \mathrm{eV}^{[4]}$. As shown in Figure 1, a GaAs substrate, although subjected to chemical cleaning has yet oxides. Indeed, there is a contribution located at $20,4 \mathrm{eV} \pm 0,2 \mathrm{eV}$ which corresponds to the $\mathrm{Ga}-\mathrm{O}$ bonds attributed to gallium oxide $\mathrm{Ga}_{2} \mathrm{O}_{3}{ }^{[4,5]}$. The analysis also shows that the transition ion bombardment of the substrate does not involve the formation of metallic gallium on the surface. In fact, the $\mathrm{Ga}_{3 \mathrm{~d}}$ transition has not a contribution of metalic gallium at $0,7 \pm 0,2 \mathrm{eV}^{[4]}$ towards lower bond energies. The parameters of the decomposition peak shape and width at half height of a peak in a given transition, are determined from the decay of the peak in the cleaned substrate. We considered that the width at half height of a transition is independent of the nature of the chemical bond. Note that the peak intensities of photoelectrons are measured relative to a reference sample or placed in the test chamber.

The decomposition parameters of the $\mathrm{Ga}_{3 \mathrm{~d}}$ transition are ${ }^{[1]}$ :

- Width at half-height : $1,8 \pm 0,2 \mathrm{eV}$; 
- Peak shape : $20 \%$ gaussien - $80 \%$ lorentzien.

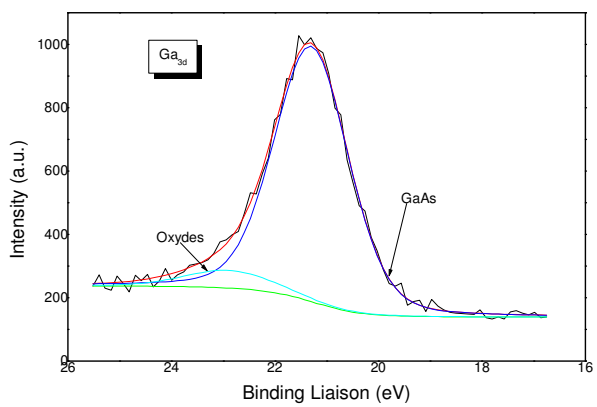

Figure 1: Spectrum of the $\mathrm{Ga}_{3 \mathrm{~d}}$ transition after chemical cleaning

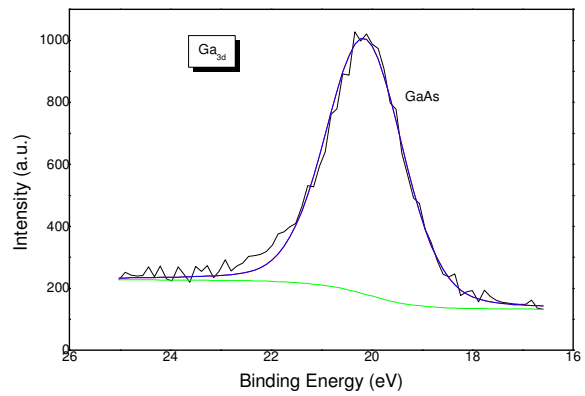

Figure 2: Spectrum of the $\mathrm{Ga}_{3 \mathrm{~d}}$ transition after ionic cleaning

\subsection{Study of the As3d transition}

This transition is shown in Figure 3. It represents the XPS spectrum of the $\mathrm{As}_{3 \mathrm{~d}}$ transition cleaning after $60 \mathrm{~min}$ with argon ions. It includes only the contribution As-Ga bonds which is located at $40,8 \pm 0,2 \mathrm{eV}^{[4,6]}$. This contribution is divided into doublet $\mathrm{As}_{3 \mathrm{~d} 5 / 2}$ and $\mathrm{As}_{3 \mathrm{~d} 3 / 2}$ related to spin-orbit coupling with the gap in the doublet is $0,7 \mathrm{eV}$ and which the area ratio is between 1,2 and 1,4 .

The parameters of the decomposition peak shape are ${ }^{[1]}$ :

- Width at half-height : 1,6 $\pm 0,2 \mathrm{eV}$;

- Peak shape : $50 \%$ gaussien - 50\% lorentzien.

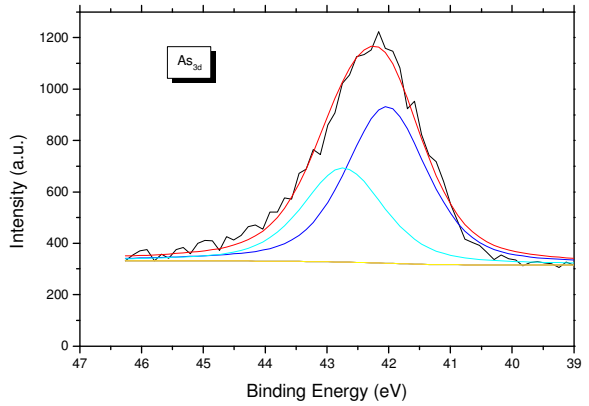

Figure 3: Spectrum of the $\mathrm{AS}_{3 \mathrm{~d}}$ transition after ionic cleaning

\subsection{Study nitriding substrates}

We studied the nitridation of GaAs using as a source of nitrogen production assets, the source type radio-frequency plasma. We prepared samples nitrided at a temperature of 550 ${ }^{\circ} \mathrm{C}$ and a pressure of $2 \times 10^{-4} \mathrm{~Pa}$.

Figure 4 shows the spectrum of the $\mathrm{Ga}_{3 \mathrm{~d}}$ transition after nitriding. This transition has a new contribution at $0,7 \pm 0,2$ $\mathrm{eV}$ towards higher binding energies. It corresponds to the Ga$\mathrm{N}$ bonds ${ }^{[2,7]}$. The parameters used for the decomposition $\mathrm{Ga}_{3 \mathrm{~d}}$ nitrided were kept identical to those of $\mathrm{Ga}_{3 \mathrm{~d}}$ cleaned.

This transition also includes a contribution due to oxides of gallium. The oxidation rate is $13 \%$ of the surface of the $\mathrm{GaN}$ bonds. This oxidation is attributed to experimental conditions such that the residual pressure of oxygen in the deposition chamber.

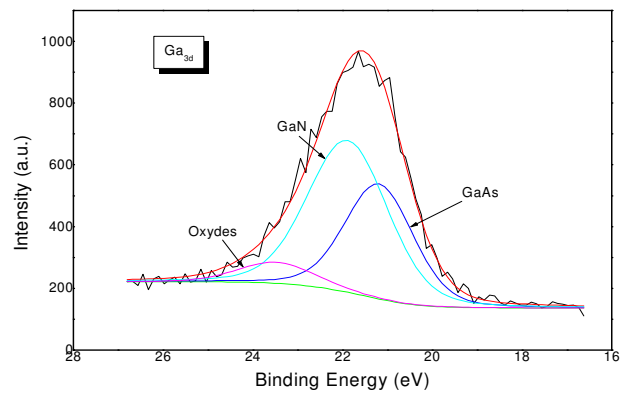

Figure 4: Spectrum of the $\mathrm{Ga}_{3 \mathrm{~d}}$ transition after nitridation

Figure 5 shows the $\mathrm{N}_{1 \mathrm{~s}}$ transition. It includes a contribution located at $397 \mathrm{eV}$ associated with $\mathrm{Ga}-\mathrm{N}$ bonds ${ }^{[8]}$ and a contribution located at $2.5 \mathrm{eV}$ to higher energies. This contribution is attributed to bonding states of (N-Ga-O) type content in the nitride film.

The decomposition parameters of the $\mathrm{N}_{1 \mathrm{~s}}$ transition are ${ }^{[1]}$ :

- Width at half-height : $2,2 \pm 0,2 \mathrm{eV}$;

- Peak shape : 50\% gaussien - 50\% lorentzien.

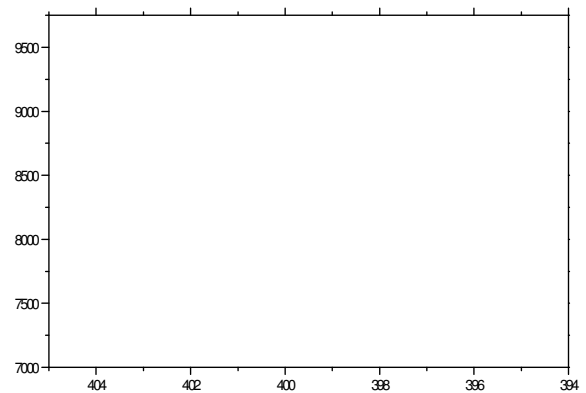

Figure 5: Spectrum of the $\mathrm{N}_{1 \mathrm{~S}}$ transition after nitridation

Figure 6 shows the $\mathrm{As}_{3 \mathrm{~d}}$ transition. It comprises in addition to the associated pair of links with the substrate, a contribution located at $1,4 \pm 0,2 \mathrm{eV}$, to higher energies. This contribution is probably due to connections arsenic oxides ${ }^{[9]}$. 


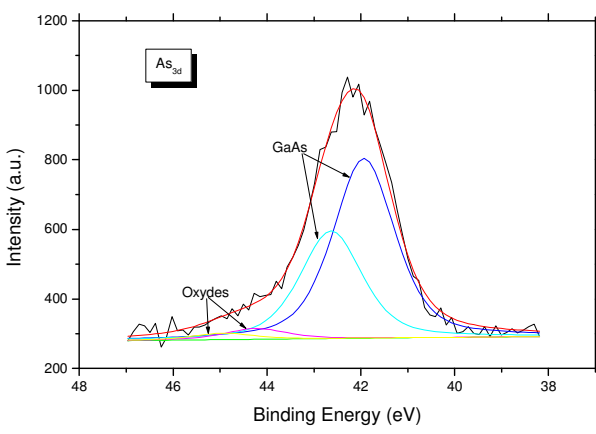

Figure 6: Spectrum of the $\mathrm{As}_{3 \mathrm{~d}}$ transition after nitridation

\section{Electrical characterization}

\subsection{Numerical modeling :}

The main process of electrical conduction observed in a Schottky diode are :

- The thermionic emission of carriers who can cross the barrier. The expression that connects the current potential applied directly on the diode is ${ }^{[10]}$ :

$$
I(V)=I(0) \times \exp \left(\frac{q \times V-R_{S} \times I}{n \times K_{B} \times T}\right)
$$

Where $\mathrm{V}$ is the direct applied bias, $\mathrm{n}$ is the ideality factor, $\mathrm{Rs}$ is the series resistance of the diode, $\mathrm{I}(0)$ is the saturation current.

With ideality factor near 1 .

- The recombination of carriers on deep centers generationrecombination. The current follows, again, the law of variation given by equation (1), with ideality factor near 2 .

- The tunneling of electrons through the potential barrier of semiconductor to the metal. The tunnel effect can be observed, under direct polarization in the case of a degenerate semiconductor.

The equation of tunnel current is given by the following equation ${ }^{[10]}$ :

$$
\begin{array}{r}
\operatorname{Itu}(V)=\operatorname{Itu}(0) \times \exp \left(\frac{V-R_{\mathrm{s}} \times I}{E_{0}}\right) \\
\text { where : } E_{0}=E_{00} \times \operatorname{coth}\left(\frac{\mathrm{q} \times \mathrm{E}_{00}}{\mathrm{k}_{\mathrm{B}} \times \mathrm{T}} \pi\right) \\
\text { With : } \mathrm{E}_{00}=\mathrm{q} \times \frac{\hbar}{2} \sqrt{\frac{\mathrm{N}_{\mathrm{d}}}{\varepsilon_{0} \varepsilon_{\mathrm{s}} \mathrm{m}_{\mathrm{e}}^{*}}}
\end{array}
$$

- If there is a highly conductive layer at the metalsemiconductor interface, which is the origin of leakage currents in the diode, the current may be due to the effect of a parallel resistance $R_{p}$. The term of this current is ${ }^{[10]}$ :

$$
\mathrm{I}_{\mathrm{R}_{\mathrm{P}}}(\mathrm{V})=\frac{\mathrm{V}-\mathrm{R}_{\mathrm{S}} \times \mathrm{I}}{\mathrm{R}_{\mathrm{p}}}
$$

This is more likely when the level of reverse current is high enough.

\subsection{Electrical measurements}

To study the effect of nitriding of electronic devices based on GaAs, I-V characterization was made on nitrided GaAs on GaAs chemically cleaned and non-nitrided. For an electronic device, a ball of mercury is applied onto the two structures. The result of the direct I-V characterization is shown in Figure 7. This figure shows that we have a current gain important for the structure based on GaAs nitrided structure which corresponds to a rectifier. We explain this in that the nitridation of GaAs has the effect of preventing oxidation of the surface. In addition, the GaN layer obtained is very thin $(\approx$ $30 \AA$ ), so the resulting structure is actually a Schottky diode $\mathrm{Hg} / \mathrm{GaAs}$ with a GaAs surface treated by nitriding.

Figure 8 shows the direct and reverse I-V characteristic of the $\mathrm{Hg} / \mathrm{GaN} / \mathrm{GaAs}$ structure on a semi-logarithmic scale. This figure shows that the direct characteristic contains two parts corresponding to two different conduction models. For bias voltages greater than $0.55 \mathrm{~V}$, the characteristic is dominated by the series resistance effect with a conduction due to the phenomenon of generation-recombination because the ideality factor is about 2. However, the reverse saturation current, the series resistor, the parallel resistor and the potential barrier height are respectively measured at :

$\mathrm{I}_{\mathrm{S}}=2,5 \cdot 10^{-6} \mathrm{~A} ; \mathrm{Rs}=13 \Omega ; \mathrm{Rp}=500 \Omega ; \Phi_{\mathrm{BN}}=0,63 \mathrm{eV}$.

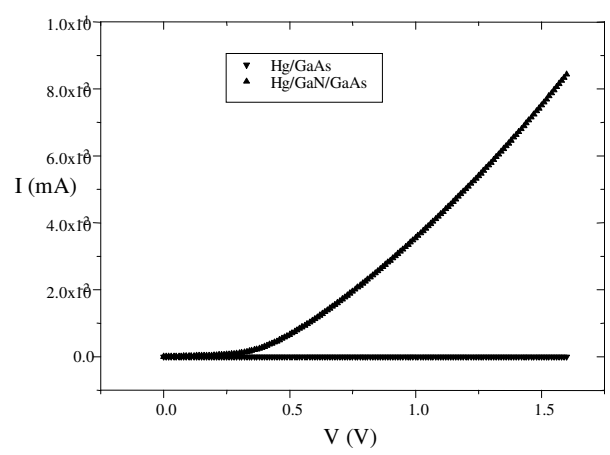

Figure 7: Direct I-V Characteristics for $\mathrm{Hg} / \mathrm{GaAs}$ and $\mathrm{Hg} / \mathrm{GaN} / \mathrm{GaAs}$ structures

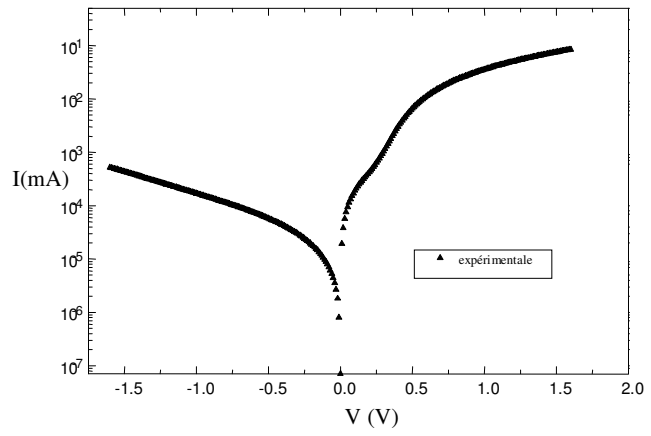

Figure 8: Direct and reverse I-V Characteristic for the $\mathrm{Hg} / \mathrm{GaN} / \mathrm{GaAs}$ structure

\section{Conclusion}

In this work, we have demonstrated the effectiveness of the process of nitriding of $\mathrm{GaAs}$ for obtaining the first $\mathrm{GaN}$ layers. We have demonstrated the interest of the photoelectron spectroscopy (XPS) for the control of surface evolution based treatments applied to the surface of the substrates. This 
International Journal of Science and Engineering Applications

Volume 2 Issue 4,2013, ISSN-2319-7560 (Online)

analysis also enables us to know the elements present on the surface as well as the elements which are connected. We noticed that the nitridation of GaAs at the same time causes the oxidation of the surface oxidation that we assigned to experimental conditions such that the residual pressure of oxygen in the deposition chamber.

I-V Electrical measurements on two structures type $\mathrm{Hg} / \mathrm{GaAs}$ et $\mathrm{Hg} / \mathrm{GaN} / \mathrm{GaAs}$; the second structure looks rectifier with high current gain while the first structure did not. We also determine from the I-V characteristic obtained for the structure $\mathrm{Hg} / \mathrm{GaN} / \mathrm{GaAs}$ some electrical parameters of the developed structure.

\section{REFERENCES}

[1] Y. Ould-Metidji Thèse de Docteur d'Université, Université Blaise Pascal (2002).

[2] L.A. DelouiseJ. Vac. Sci. Technol. A10 (4), (1992). 1637.

[3] L.A. Delouise J. Vac. Sci. Technol. A11 (3), (1993). 609.

[4] J.F. Moulder, W.F. Stickle, P.E. Sobol, K.D. Bomben Hand Book of X-ray Photoelectron Spectroscopy ; Edité par J. Chastain, Publié par Perkin-Elmer corporation (1992)

[5] J.L. Sullivan, W. Yu, S.O. Saied Applied Surface Science. 90 (1992) 515.

[6] Hand Book of X-ray Photoelectron Spectroscopy Edition JEOL (1991)

[7] J.S. Pan, C.H.A. Huan, A.T.S. Wee, H.S. Tan, K.L. Tan J. Mater. Res. 13 (7), (1998) 1799.

[8] P. Hill, J. Lu, L. Haworth, D.I. Westood, J.E. Macdonald Applied Surface Science. 123/124 (1998) 126.

[9] Y. Misokawa, H. Iwasaki, R.Y. Nishitani, S. Nakamura J. of Electron Spectroscopy and Related Phenomena. 14 (1978) 129.

[10] A.M.J.F. Philippe Thèse de Docteur d'Université, Institut National des Sciences de Lyon (1999). 